\title{
Metaficção historiográfica - diálogos entre o discurso histórico e o literário nos romances latino-americanos
}

\author{
Weslei Roberto Cândido*
}

O presente texto tem por objetivo discutir as relações entre literatura e história a partir da análise e discussão de fragmentos dos romances Vigilia del Almirante, de Roa Bastos e Galvez, o imperador do Acre, de Márcio Souza, apontando como essa literatura está em constante intertextualidade com o discurso da história. Também, apresentaremos como a pós-modernidade contribuiu ao assumir que tanto a literatura como a história são construções discursivas passíveis de revisão, portanto, como constructos ambas passam, em certa medida, pela ficcionalização de seus autores, sendo a primeira compromissada com a arte e a segunda com a verdade.

Palavras-chave: Metaficção historiográfica; novo romance histórico; pós-modernidade.

This paper aims to discuss the relationship between literature and history from the analysis
Para la ficción no hay textos establecidos.

- Roa Bastos -

\section{Introdução}

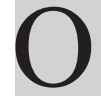

presente artigo visa discutir as relações entre literatura e história no chamado novo romance histórico latino-americano, mais propriamente partindo de dois romances: Vigilia

*Doutor-UEM - wrcandido@uem.br 
and discussion of fragments of novels Vigilia del Almirante, by Roa Bastos and Galvez, imperador do Acre, by Márcio Souza, pointing out how this literature is constantly intertextuality with the discourse of history. Also, introduce how postmodernity has contributed to assume that either literature and history discur- sive constructions are subject to revision, so as constructs both are, to some extent, by the fictionalization of the authors, the first being committed to the art and second with the truth.

Keywords: Historiographic metafiction, new historical novel; postmodernity

del Almirante, de Augusto Roa Bastos ${ }^{1}$ e de Galvez, o imperador do Acre, de Márcio Souza ${ }^{2}$ em contraponto com alguns conceitos levantados por Linda $\mathrm{Hu}-$ tcheon em Poética do Pós-Modernismo ${ }^{3}$, no qual são discutidas questões sobre a discursividade literária e historiográfica e como as duas estão em diálogo por meio daquilo que se intitula metaficção historiográfica.

Desta maneira, nosso foco não será o romance histórico no sentido tradicional, no qual uma personagem histórica figura como centro da narrativa e partir dela se narra os fatos, mas nos centraremos em romances que discutem de forma indireta o que vem a ser o discurso histórico e o literário, em que medida ambos interagem, completando-se e excluindo-se ao mesmo tempo, sem que, na verdade, jamais um venha a descartar o outro totalmente.

Nosso ponto de partida será a pós-modernidade e como esta incorpora o passado sem negá-lo, constituindo seu paradoxo, pois ao mesmo tempo que parodia o passado, ou melhor, as formas textuais do passado, as sacraliza, uma vez que o leitor acaba por ter como pano de fundo esses textos e os revê com os olhos do presente, permitindo manipulá-lo ao seu prazer, constituindo-se também em autor do texto.

Assim, por meio dos romances citados acima, discutiremos como episódios da descoberta da América e da fundação do Acre como um estado independente são relidos e ficcionalizados por seus autores, que também problematizam suas ficções, admitindo as dívidas com a história e como dela fazem uso nos seus romances.

\footnotetext{
${ }^{1}$ ROA BASTOS, Augusto. Vigilia del almirante. Asunción. Paraguay: RP Ediciones, 1992.

${ }^{2}$ SOUZA, Márcio. Galvez, imperador do Acre. 10ed. Rio de Janeiro: Marco Zero, 1983.

${ }^{3}$ HUTCHEON, Linda. Poética do pós-modernismo. Trad. Ricardo Cruz. Rio de Janeiro: Imago, 1991.
} 
Lidaremos, portanto, com um gênero híbrido, que usa de dois artifícios narrativos conscientemente: o literário e o histórico, ora agindo como romancista ora como pseudo historiador, ludibriando a cada instante o leitor que fica em dúvida se o texto romanesco tem o poder de apresentar uma nova versão da história que seja válida.

De acordo com Altamir Botoso:

Observa-se, nesse sentido, um aumento progressivo no recurso à intertextualidade pela literatura de ficção, com a retomada de textos e personagens da história. Os autores de livros ficcionais passaram a considerar as produções historiográficas como textos passíveis de serem recriados, parodiados e distorcidos. Portanto a história e a ficção são consideradas como modalidades discursivas, fato que levou Hayden White(1994, p.98) a classificar os eventos históricos como "narrativas históricas", que manifestamente são "ficções verbais cujos conteúdos são tanto 'inventados' quanto 'descobertos' e cujas formas têm mais em comum com os seus equivalentes na literatura do que com seus correspondentes nas ciências". O texto escrito por historiadores pode ser considerado um "artefato literário" que mantém vínculos estreitos com as narrativas de ficção ${ }^{4}$.

Esse vínculo estreito entre a forma de narrar da literatura e da história e sua aproximação com a ficcionalização em alguns momentos, que nos permitirá colocar em diálogo a literatura e a história, verificando como se imbricam, assumindo-se efetivamente como construções discursivas que remetem a um passado "real" ou "ilusório". Essa linha tênue entre a verdade e a ficção que tentaremos explorar ao longo deste artigo, citando em vários momentos as falas de Roa Bastos e de Márcio Souza, como apoio e material de análise de nossas preocupações ao discutir essas formas discursivas tão próximas.

Portanto, tentaremos explorar as confluências que há entre os dois gêneros textuais em questão: o historiográfico e o literário e como eles se imbricam, rechaçam-se e se aproximam constantemente, confundindo muitas vezes a figura do romancista com a do historiador e vice versa. Assim, poderemos explorar como o novo romance histórico na América Latina se tornou uma espécie de recurso ideológico para contestar a cultura dominante por meio da paródia, do pastiche, do humor e do riso fácil, debatendo como esses elementos ajudam a

\footnotetext{
${ }^{4}$ BOTOSO, Altamir. A reescritura da história em o Mundo alucinante de Reinaldo Arenas. Bauru: Canal 6, 2010, p.57.
} 
desconstruir o discurso da história arquitetada pelas elites europeias e crioulas no continente americano.

\section{Entre o discurso da história e da literatura}

A pós-modernidade trouxe consigo a vantagem de assumir os textos como constructos e, portanto, como passíveis de serem revistos e reinterpretados, sem que necessariamente a interpretação do fato seja invalidada, mas permanece como ponto de discordância e revisões inúmeras que não podem descartar o texto primeiro. Como espécie de sombra, o texto "original" serve de ponto de partida para as revisões do passado, criando um espaço de convivência entre diversos textos e diversas interpretações do mesmo fato.

Nesse espaço de confluências e embates há dois gêneros textuais que se chocam, complementam-se, vivem sob o olhar enviesado da desconfiança que são os textos históricos e os literários, ambos atendendo a necessidades diferentes, mas atraindo leitores para o mesmo fato por meios diversos e conflitantes.

O chamado novo romance histórico latino-americano se presta a essas discussões e reinterpretações da história da América, invadindo um terreno que não é seu, do qual se apropria para deleite literário, por meio da paródia, do pastiche e de inclusão de novos acontecimentos e personagens a fatos históricos já consagrados, mas que a literatura pelo seu caráter se dá o direito de alterar para colocar em dúvida o leitor, muitas vezes oferecendo a este uma visão muito mais agradável que o da clássica história dos vencedores, pois ao narrar da margem fatos históricos antes vistos apenas pelo olhar da elite, inclui aquele que foi esquecido ao longo do processo colonizatório, ou seja, o próprio habitante do continente americano.

Vem somar-se a essas dúvidas do leitor o próprio momento vivido pelos historiadores, que também ao assumir ser o texto da História um constructo, uma análise sobre um fato realmente ocorrido, abre margem para dúvidas e releituras da colonização americana pelos intelectuais da América, que ao revisar documentos históricos, consultar fontes e ter acesso a materiais antes privados, podem lançar um novo olhar sobre a forma como o continente sofreu com a implantação do regime europeu de vida naquilo que eles chamavam de Novo Mundo. 
No entanto, novo romance histórico e o texto histórico em si são meios diferentes de ver a história, um não substitui o outro, mas tem seu contraponto no seu oposto. De acordo com Linda Hutcheon, o discurso da história e o da ficção não fazem parte da mesma ordem de discurso:

[...] são diferentes, embora tenham os mesmos contextos sociais, culturais e ideológicos, e também as mesmas técnicas formais. Os romances (com exceção de algumas superficções extremas) incorporam a história social e política até certo ponto, embora essa proporção seja variável (Hough, 1966, 113); a historiografia, por sua vez, é tão estruturada e coerente e teleológica quanto qualquer ficção narrativa. Não é só o romance, mas também a história, que está 'visivelmente entre e no meio'(Kermode 1968', 235). Tanto historiadores quanto os romancistas constituem seus sujeitos como possíveis objetos de representação narrativa[...]. ${ }^{5}$

Embora sendo da ordem de discursos distintos, é inegável o diálogo estabelecido entre esses dois meios de narrativa da história, um compromissado com a verdade e o outro com a ficção, ambos se relacionando com a história, com a sociedade e com a política, cada um por meio de seus instrumentos textuais que garantem ao leitor uma revisão do passado pelos olhos do historiador ou do narrador estabelecido pelo romancista. Tanto a ficção como a história estabelece para si sujeitos, construindo seus personagens ora para exaltá-los ou verificar seu papel no quadro histórico ora para rebaixá-los ao nível dos seres humanos comuns, como resposta a todo um discurso eurocêntrico que transformou os colonizadores em heróis brancos que deveriam ser exaltados pelo povo nativo das Américas. A esse segundo papel revisionista, mas cheio de (in)verdades também cabe à ficção seu espaço maior, uma vez que não está compromissada com a verdade, mas com a representação de uma pretensa verdade válida para contextos criados pelos romances.

Portanto, está fora de cogitação que algum dia o novo romance histórico se torne a base interpretativa da história dos países americanos. Ele é ficção e como tal deve ser lido e interpretado, mesmo que esteja ligado a um contexto histórico-político-social, este é apenas o estímulo para a criatividade exercida pelo autor para olhar a América pelos seus olhos, pela paródia muitas vezes do discurso histórico, apresentando-se como uma verdade inexorável, que só pode ser questionada porque é uma forma de questionar o próprio discurso histórico canônico.

${ }^{5}$ HUTCHEON, Linda. Op. cit., p. 148. 
Augusto Roa Bastos no prólogo a seu romance Vigilia del Almirante(1992), afirma categoricamente o caráter de seu romance diante da história:

Este es un relato de ficción impura, o mixta, oscilante entre la realidad de la fábula y la fábula de la historia. Su visión y cosmovisión son las de un mestizo de "dos mundos", de dos historias que se contradicen y se niegan. Es por tanto una obra heterodoxa, ahistórica, acaso anti-histórica, anti-maniquea, lejos de la parodia y del pastiche, del anatema y de la hagiografía. ${ }^{6}$

O romance de Augusto Roa Bastos é uma clara releitura da figura do navegador Cristóvão Colombo; como todo romance de caráter histórico tem como centro uma personagem também histórica e, nesse caso, de fundamental importância para o continente americano. O livro está inserido num contexto social de produção objetiva: a comemoração dos 500 anos da América, que gerou uma série de romances nessa linha revisionista das principais figuras históricas que participaram dos momentos de implantação das colônias no Novo Mundo.

A fala de Roa Bastos é esclarecedora sobre o papel desse novo romance histórico na América Latina. Assume livremente ser um relato de "ficção impura", entre a história e a invenção literária, entre duas fábulas: a da realidade, que é uma, e da história que é outra, legitimamente pensada e arquitetada para ser a história canônica. Além disso, o autor assume seu papel de produto de dois mundos, de duas histórias que se contrapõem: a da versão espanhola sobre a colonização do continente americano e a dos americanos, que agora depois de 500 anos podem contar a história pelo seu ponto de vista, da perspectiva dos "mestizos", daqueles que se tornaram realmente o povo do continente em questão.

Não há em Roa Bastos nem a intenção de transformar Colombo em anátema, nem tampouco fazer sua hagiografia, como a maioria dos escritores da América Latina que seguem a linha do novo romance histórico, levando à conclusão de que para estes escritores a história tradicional transforma os sujeitos da história em anátemas ou em santos (hagiografia). Quer apenas humanizar a figura de Colombo, transformá-lo em um ser mais próximo das pessoas que habitam o continente: 'Quiere este texto recuperar la carnadura del hombre común[...]'. Assim se expressa o autor, revelando que o texto, ou seja, novamente o discur-

${ }^{6}$ ROA BASTOS, Augusto. Op. cit., p. 11.

${ }^{7}$ Idem. 
so tem como objetivo recuperar o lado humano de Cristóvão Colombo, assim, revela-se o texto do autor paraguaio também como um constructo que se oferece como mais uma alternativa ao discurso histórico legitimado pelos saberes das academias.

Desta maneira, o discurso literário e o histórico se mostram muito próximos, cada um com suas devidas particularidades, mas ambos como textualizações de discursos legitimados por suas áreas, o primeiro preso aos cânones literários existentes, o segundo preso ao compromisso de reconstruir a realidade passada, porém tanto o literato quanto o historiador se apresentam como intérpretes de suas áreas e dos conceitos a elas ligados.

No entanto, há no literato um compromisso maior com a invenção, com a criação literária, com o fazer a arte com palavras, em contar a história mais pelo como do que pelo fato. Novamente, citando o prólogo de Roa Bastos, o autor afirma: "[...] un autor de historias fingidas escribe el libro que quiere leer y no encuentra en ninguna parte; ese libro que sólo puede leer una vez en el momento en que lo escribe[...]"8.

É visível o contraponto com o texto da história oficial, ela está presente no horizonte de expectativas do romancista, que não o perde de vista, mas por ser compromissado com a literatura, pode escrever o livro que deseja e não encontra, pode arquitetar sua história da descoberta da América, poder olhá-la como este "mestizo de dos mundos". Recuperar "la historia que le robó su nombre. Necesitó quinientos años para nacer como mito. Para recuperar esta história, porém, o autor se dá o direito de construir a sua, do seu ponto de vista, pela ótica que mais lhe interessa, praticando o que ele chama de "transgresiones con relación a los textos canónicos" que são "deliberados pero no arbitrarios ni caprichosos".

O diálogo entre ficção e história se acirra ainda mais quando pensamos que tanto o historiador quanto o literato e até mesmos os leitores possuem uma capacidade limitada de compreender o passado ${ }^{9}$. Lidamos com retalhos do passado, com sobras dos arquivos, com materiais também já pré-selecionados para se tornarem documentos a partir de uma determinada concepção de história de sua época; de certa maneira, trabalha-se com aquilo que restou como recorte da

\footnotetext{
${ }^{8}$ Idem, p. 11-12.

${ }^{9}$ HUTCHEON, Linda. Op. cit.,
} 
realidade do passado, mas que é a ponte com uma possibilidade de reconstrução de uma determinada época, portanto, novamente, o trabalho do literato e do historiador se cruza, ambos lidam com reconstrução e representação de uma dada realidade, a partir de determinadas realidades históricas em que estão inseridos, sendo obrigado a olhar para trás a fim de encontrar os vestígios que colarão os cacos do vaso quebrado da história.

Em "Metaficção Historiográfica: o passatempo do tempo passado", Linda Hutcheon afirma que:

A metaficção historiográfica sugere uma distinção entre "acontecimentos" e "fatos" que é compartilhada por muitos historiadores. Como venho sugerindo, os acontecimentos tomam forma de fatos por meio de sua relação com matrizes conceituais em cujo interior precisam ser embutidos se tiverem de ser considerados como fatos. ${ }^{10}$.

O acontecimento está para o escritor de romances assim como para o historiador em vias de se tornar fato. Para o primeiro, material literário que transgride as normas lógicas de interpretação e garante a ele(ao acontecimento) o tornar-se fato literário dentro da arquitetura do romance; para o segundo, o acontecimento se torna fato ao ser interpretado por matrizes lógicas da historiografia que garantem a ele o status de fato histórico disponível para as mais diversas interpretações e discussões. Para o romancista o compromisso é com a fantasia, com o fazer poético, para o historiador, o foco é a verdade, o desvendamento dos acontecimentos, que ao se tornarem fato ajudarão a sociedade a compreender melhor seus processos se construção política e econômica.

Em outro romance latino-americano vê-se o trabalho do romancista e a liberdade que se permite ao interpretar ou reinterpretar os fatos à luz de suas necessidades, senão pessoais, a menos literárias. Numa espécie de nota explicativa, quase um prólogo, mas bem mais conciso que a maioria dos prólogos dos livros tradicionais a Galvez, o imperador do Acre, o autor faz a seguinte afirmação sobre os fatos que seguem narrados:

Este é um livro de ficção onde figuras da história se entrelaçam numa síntese dos delírios da monocultura. Os eventos do passado estão arranjados numa

${ }^{10}$ Idem, p. 161. 
nova atribuição de motivos e o autor procurou mostrar uma determinada fração do viver regional ${ }^{11}$.

O primeiro alerta que se deve levar em contar é o fato de ser declaradamente ficção, mesmo que trate de um evento histórico, a independência do Acre, seu desligamento da Bolívia, o que vai narrado é invenção e nessa estão incorporadas figuras históricas que transitarão nos "delírios da monocultura". Além disso, os fatos do passado foram (re)arranjados de forma a dar ao livro a configuração que desejava, os motivos são declaradamente outros, novos, adequados ao romance em tom de história picaresca que é o romance de Márcio Souza.

O romance é uma brincadeira com a história oficial, manipulando-a ao prazer do romancista, que inclui o humor, a ironia, a paródia como formas de criação artística. A História com maiúscula é apenas o pano de fundo, onde personagens também históricos como Galvez desfilarão seus desejos, suas vontades e picardias na construção do território hoje conhecido como Brasil. Logo após o prólogo, em forma de epígrafe, surge o provérbio português: “Além do equador tudo é permitido." ${ }^{\prime 2}$, para em seguida, em tom de deboche, o protagonista afirmar: "Nem tudo"13, com o acréscimo do contexto que gerou essa reflexão: a deposição do imperador Galvez, que experimentou viver o provérbio e sofreu as consequências com a deposição de seu cargo.

Em tom de brincadeira e deboche o romance tenta reconstruir episódios do período áureo da exploração da borracha no Brasil. O riso o tempo todo destrona a história oficial, tirando sua seriedade, relendo os episódios históricos pelo olhar da paródia, do pastiche, do romance picaresco. É significativo o fato de Galvez ser um aventureiro espanhol em terras brasileiras, buscando ascensão política e financeira, mesmo que seja como Imperador do Acre, nunca oficialmente reconhecido.

Tudo no romance depõe contra a história oficial. O palácio de Galvez não passa de um antigo barracão de zinco que servia de estoque da borracha tirada da selva. Para desfigurar ainda mais a oficialidade da história tradicional, esse palácio/barracão ganha uma luxuosa escada de mármore:

\footnotetext{
${ }^{11}$ SOUZA, Marcio. Op. cit., p. 5.

${ }^{12}$ Idem, p. 6.

${ }^{13}$ Idem.
} 
A escada de mármore, pré-montada no Liceu de Artes e Ofícios de Lisboa pelo preço de 700 libras formava um conjunto bizarro com o barracão imperial. $\mathrm{O}$ mármore raiado de rosa contrastava com a madeira escura do Palácio Imperial e $\mathrm{m}$ anda correspondia com as proporções do pardieiro de zinco enferrujado. Os lances de degraus majestosos não levavam a lugar nenhum, numa metáfora ao meu Império. ${ }^{14}$.

O próprio Galvez, agora imperador, reconhece a bizarrice da escada de mármore, plantada no meio da selva amazônica, adaptada a um barracão velho que fora transformado em palácio. Percebe-se ainda nesse fragmento o trabalho literário, o narrador personagem admite a metáfora, o constructo literário e ideológico que aquela escada representava, nem permitindo ao leitor pensar em interpretar algo que é patente demais para se perder tempo. De certa forma, o leitor acompanha o delírio de formação do Acre por meio do narrador que assume todas suas falhas e narra o que há de pior em sua figura. Ao contrário dos grandes personagens históricos, Galvez é o aventureiro, e como tal deixa sua história.

Em geral, o novo romance histórico latino-americano tem sido visto como uma alternativa à história oficial do continente. No entanto, esses romances que levam ao questionamento dos episódios históricos da formação da América são literatura, e como literatura devem ser lidos, até mesmo para se apropriar das rebeldias contra a história oficial que esse romance provoca. $\mathrm{O}$ novo romance histórico latino-americano vive e revive por meio deste diálogo com o discurso oficial, o desrespeito a ele é uma forma d resistência às estruturas sociais impostas pelo colonizador aos habitantes do continente americano.

Por isso, pode-se afirmar que o novo romance histórico latino-americano é típico da pós-modernidade que não despreza o passado mas o incorpora de forma crítica ao seu arsenal criativo. Não se renuncia mais ao passado, mas este está presente até mesmo na negação de como foi contado oficialmente pelos historiadores. De certa maneira, o novo romance histórico sabe que não pode se livrar da História, então, alia-se a ela, reproduzindo ao seu modo os episódios da história que só ganham tom de humor porque agridem os textos históricos sacralizados pelas instituições oficiais que arquitetaram as nações latino-americanas.

A paródia dos textos históricos e literários é frequente na metaficção historiográfica; parodiam-se os discursos da história e da literatura, questiona-se

${ }^{14}$ Idem, p. 191. 
o artifício literário e histórico de herança europeia, fazendo com que o novo romance histórico latino-americano parodie estruturas discursivas, mais do que fato propriamente ditos, questiona-se de certa forma o "conceito realista ingênuo de representação" 15 . Assim, mais que a paródia dos fatos, tem-se a paródia dos discursos estético e historiográfico naquilo que se costumou chamar de metaficção historiográfica que alcançou vários autores no continente americano.

No entanto, para Linda Hutcheon ${ }^{16}$ : "a paródia não é a destruição do passado; na verdade, parodiar é sacralizar o passado e questioná-lo ao mesmo tempo. E, mais uma vez, esse é o paradoxo pós-moderno." Assim, autores como Roa-Bastos e Márcio Souza que têm servido até agora de base para as discussões propostas aqui não negam o passado, incorporam-no em forma de paródia dos discursos literários e históricos, não sendo em nenhum momento um texto que quer substituir o historiográfico, mas sim que entra em forte diálogo com o material discursivo que interpretou a história das repúblicas latino-americanas.

É desta maneira, por exemplo, que Márcio Souza imita ou parodia, ou reinventa o trabalho do historiador, que num sebo encontra um antigo manuscrito (fontes) que ninguém deu importância, mas que ele, o autor, comprou barato e depois de trabalhá-lo deu a forma de romance e o publicou:

Como toda história de aventuras que se preza, o manuscrito foi encontrado num sebo de Paris, em 1973, por um turista brasileiro. Até hoje não se sabe como esse manuscrito saiu e Cádiz e foi parar na prateleira de um sebo do Boulevard Saint Michel. O certo é que o brasileiro que andava fuçando as livrarias de Paris, adquiriu o manuscrito redigido em português, pela quantia de trezentos e cinquenta francos, o que na época não era um preço alto. $O$ justo valor para um manuscrito irrelevante. $\mathrm{O}$ brasileiro leu o manuscrito em dois dias pensando em José de Alencar, que havia feito o mesmo no livro GUERRA DOS MASCATES, decidiu organizá-lo e publicar. O turista brasileiro era eu e acabei impressionado com as sandices desse espanhol do século XIX. ${ }^{17}$.

A lenda do manuscrito achado e tão repetido na literatura está de volta em Márcio Souza, aqui de forma irônica, mas presente nesse texto que não se propõe substituir o material historiográfico sobre o desligamento do Acre da Bolívia,

\footnotetext{
${ }^{15}$ HUTCHEON, Linda. Op. cit., p. 165.

${ }^{16}$ Idem.

${ }^{17}$ SOUZA, Marcio. Op. cit., p. 14.
} 
mas sim admitidamente contar uma história de aventuras. A paródia escancarada do projeto literário de Alencar de contar a genealogia do povo brasileiro com seus romances mostra bem o trabalho literário da metaficção historiográfica, pois dialoga com duas formas discursivas: a literária, o romance alencariano, e a historiográfica, a vida de Galvez, e também a forma de produção de um dos mais consagrados romancistas brasileiros da época de afirmação da identidade nacional. Percebe-se, nitidamente, que a paródia não é apenas factual, mas rompe com a forma de representação ingênua do realismo tradicional que acreditava poder por meio de longas transcrições recriar o real.

O fragmento de Galvez, o imperador do Acre revela ainda que o texto da ficção está em pleno diálogo com as tendências literárias anteriores e a elas faz referências, comunga com ideais e rebate outros ao fazer o texto literário. Como forma de resposta, paródia ou dessacralização do passado literário, ou melhor, das formas de fazer literatura dos escritores pertencentes ao cânone, Márcio Souza, assim como Roa-Bastos utiliza de forma crítica dos instrumentos literários de outros romancistas que compõem a tradição. De forma mais objetiva, o intertexto maior da metaficção historiográfica é o próprio material literário pertencente ao acervo cultural do romancista, aí ser uma metaficção, ficção que remete a outros fazeres ficcionais antes de ser historiográfica. De certa forma, o diálogo é duplo, dá-se com dois discursos: da literatura e o da história, mais que diálogos com os fatos em si, o que existe é um intertexto com as formas discursivas que analisam os acontecimentos para torná-los fatos ficcionais ou históricos.

O reconhecimento, na pós-modernidade, de ser a história e a ficção discursos estruturados, a partir de suas bases teóricas, libertou essas formas textuais da antiga sacralização que as cercavam, até mesmo no âmbito literário, quando uma obra era passível de releitura apenas como mera cópia, pastiche, ou por meio do cômico, paródia no sentido tradicional, ou imitação, reinando livremente o conceito de fontes e influências, na qual a obra segunda sempre era um texto menor e devedor do texto que o antecedia.

O conceito de intertextualidade libertou as obras literárias desse pejo de textos de segunda mão, colocando-as em igualdade, permitindo perceber as várias vozes que compõem um texto literário, de certa forma um texto nunca é original, mas sempre participante de um pensamento que se desenvolveu ao longo de toda uma tradição. O escritor argentino Jorge Luis Borges em "Kafka e seus 
precursores" 18 inverte a questão da dependência e mostra como o texto segundo é que permite a releitura do texto anterior, agora com olhos da atualidade, ou seja, o último texto reelabora, reconstrói, atualiza o texto primeiro.

A metaficção historiográfica, portanto, não oculta suas leituras, antes as revela como forma de construção do texto literário e pseudo-historiográfico, ficção que se quer verdade, mas verdade apenas no âmbito da economia de seu texto, que remete abertamente à história com maiúscula, mas não a substitui, nem tem essa pretensão, relê criticamente a historiografia, mas tira partido da desconfiança que a ficção desperta no leitor sobre o que é a verdade, sem nunca se assumir como tal.

O novo romance histórico latino-americano não pode ser visto fora do que é: literatura, embora sirva-se da história e a ela se remeta o tempo todo, não se pode tomar um texto literário para ser estudado como história no sentido de discurso compromissado com a verdade, o compromisso do romancista sempre é com a ficção, com a inventividade, com uma espécie de mentira que cria uma realidade possível para o leitor, que lê aquilo que desejava e jamais encontrou em um livro de história:

En efecto, las novelas mienten — no pueden hacer otra cosa - pero ésa es sólo una parte de la historia. La otra es que, mintiendo, expresan una curiosa verdad, que sólo puede expresarse encubierta, disfrazada de lo que no es. Dicho así, esto tiene el semblante de un galimatías. Pero, en realidad, se trata de algo muy sencillo. Los hombres no están contentos con su suerte y casi todos —ricos o pobres, geniales o mediocres, célebres u oscuros - quisieran una vida distinta de la que viven. Para aplacar - tramposamente - ese apetito nacieron las ficciones. Ellas se escriben y se leen para que los seres humanos tengan las vidas que no se resignan a no tener. En el embrión de toda novela bulle una inconformidad, late un deseo insatisfecho ${ }^{19}$.

O escritor peruano Mario Varga Llosa chama a atenção do leitor para um ponto essencial da literatura: a mentira. Literatura é mentira, uma é sinônima da outra, assim o leitor vive a aquela mentira como se fosse verdade e satisfaz o desejo de viver uma outra vida que não a sua, saciando o dom demoníaco de ser ou-

${ }^{18}$ BORGES, Jorge Luis. Kafka e seus precursores (1951), in Outras inquisições (1952). Obras completas. vol. 2. São Paulo: Globo, 1999.

${ }^{19}$ VARGAS LLOSA, Mario. La verdad de las mentiras. Madrid: Punto de Lectura, 2007, p. 16. 
tro como afirma o mesmo escritor. O romance para Llosa é uma armadilha feita pelo escritor e vivenciada pelo leitor, que mesmo sabendo ser um engano, vive-o, pois ele revela toda a insatisfação que tem com uma determinada realidade.

É essa insatisfação que leva o escritor paraguaio Augusto Roa Bastos, já citado no início deste artigo, a escrever seu romance, sua história, aquela que ele nunca leu em nenhum livro, portanto, tem de a escrever para reinscrever a figura de Cristóvão Colombo na história pela visão do "mestizo entre dos mundos" que ele é, herdeiro de duas culturas, de duas histórias, insatisfeito com ambas, assim, ele pode escrever o livro que nunca leu, "ahistórico, anti-histórico, anti-maniqueo" como se expressa no prólogo, admitindo ser um autor de histórias fingidas, permitindo-se então a escrever o livro que deseja ler, uma vez que seu compromisso não é com o discurso historiográfico, mas com o literário, aquele cujas mentiras podem ser verdades.

Inegável é a que essa insatisfação está ligada aos textos históricos canônicos, àqueles que construíram e interpretaram a figura de Cristóvão Colombo e a colonização do continente americano, mas ainda assim Vigilia del almirante é um texto literário, no qual a liberdade fantasiosa reina do início ao fim, na qual os eventos históricos estão reajustados de forma a dar a interpretação desejada pelo autor da viagem realizada por Colombo.

O contato entre a realidade e a imaginação torna-se cada vez mais forte e tema de discussão do narrador em Vigilia del almirante, sabedor de um discurso inventado, mas que está em intertexto com a história oficial, estabelece com o leitor o pacto da pensar o que é mais importante, os fatos imaginados ou os fatos documentados, pois estes últimos também são parte de um seleção de historiadores que os apresentaram como verdade, de forma que o leitor pode decidir aquilo que julgar melhor, uma vez que a história se reescreve para Roa Bastos na leitura operada pelo leitor:

¿Cómo optar entre hechos imaginados y hechos documentados? ¿No se complementan acaso en sus oposiciones y contradicciones, en sus respectivas y opuestas naturalezas? ¿Se excluyen y anulan el rigor científico y la imaginación simbólica o alegórica? No, sino que son caminos diferentes, dos maneras distintas de concebir el mundo y de expresarlo. Ambas polinizan y fecundan a su modo - para decirlo en lenguaje botánico - la mente y la sensibilidad del 
lector, verdadero autor de una obra que él la reescribe leyendo, en el supuesto de que lectura y escritura, ciencia e intuición, realidad e imaginación se valen inversamente de los mismos signos ${ }^{20}$.

Para o autor realidade e imaginação se complementam, embora tenham discursos diferentes, uma não existe sem a outra. Não são excludentes como pensam muitos, mas todo discurso histórico ou literário exige de seu autor, que poder ser o leitor também uma dose de imaginação e de rigor científico ao mesmo tempo, percorrendo caminhos diferentes, mas lidando com signos de uma mesma cultura que está em construção. No caso da América Latina, tendo de lidar com sua própria invenção nos discurso de Colombo e tendo de reinventá-la quinhentos anos depois a partir da visão do "mestizo entre dos mundos" que é o autor/leitor latino-americano. Ambos os discursos, o literário e o histórico levam o leitor a refletir sobre sua realidade por caminhos diversos, mas que debatem o mesmo assunto.

A liberdade proporcionada pela literatura permite ao romancista criar intertextualidades que revelam a posição histórica do mesmo. A chegada de Colombo é anterior à composição de Don Quijote de la mancha, mas nem por isso deixou de apontar semelhanças entre Colombo e Alonso Quijana, cavaleiros andantes pelo mundo em busca de suas aventuras. Essas postura do narrador de Vigilia del almirante deixa antever como joga com os textos da tradição, ora do repertório histórico e ora do cânone literário. Narra-se a chega de Colombo à América quinhentos anos depois, tendo a liberdade de quebrar as linearidades temporais e avançar e regredir no tempo de acordo com sua vontade, desestabilizando as bases lógicas da cronologia, mas revelando que agora o que importa à crítica literária é o intertexto e não mais as influências sobre um autor.

No capítulo XXI intitulado "Fragmentos de una biografia apócrifa", o narrador nos da um retrato de Cristóvão Colombo:

En un lugar de la Liguria de cuyo nombre no quiere acordarse, nació hará una cuarentena este hombre de complexión recia, crecida estatura, seco de carnes, cara alargada y enjuta, frente espaciosa con una hinchada vena en la sien derecha. El ojo izquierdo empequeñecido por una cicatriz corrugada entre la frente y el pómulo torna inquietante y perturbadora su mirada. Rojizos cabellos que han encanecido de pronto hacia la treintena de su edad. Su aspecto es autoritario y a la vez sumiso y aquiescente, del que sabe mandar y obedecer. ${ }^{21}$.

\footnotetext{
${ }^{20}$ ROSA BASTOS, Augusto. Op. cit., p. 55.

${ }^{21}$ Idem, p. 129.
} 
Além da clara intertextualidade como Don Quijote por meio praticamente de um pastiche do estilo literário de Cervantes, percebe-se que o diálogo extrapola o literário e esbarra nas construções históricas oficiais como a pintura de quadros que retratam figuras ou episódios históricos da maneira com que as instituições desejam deixar para a posteridade. Assim, sempre o que temos são construções ideológicas do passado, o que não deixa de revelar, em certa medida, o trabalho artístico do pintor ou a ficcionalização no caso do narrador da história com maiúscula. $\mathrm{O}$ fato de a citação ser parte de um capítulo intitulado "Fragmentos de una biografia apócrifa" revela ainda a intenção de construir um discurso paralelo ao da história oficial, desencavando fontes antes desconhecidas.

Para Foucault ${ }^{22}$ as categorias discursivas da história, da literatura, política, filosofia e religião não são precisas o suficiente para separá-las de forma de categórica. Digamos que a literatura tira partido dessas imprecisões e o novo romance histórico latino-americano adentra ao campo dos discursos da história reivindicando a seu modo, pelas particularidades da discursividade literária, uma revisão das interpretações históricas feitas a respeito do continente americano, por isso sempre esses romances operam de modo a descontruir as representações consagradas de figuras históricas, humanizando-as, recuperando a "carnadura del hombre común", para usar a expressão de Roa Bastos, ao revisar determinados períodos da história americana.

Foucault comenta essa inquietação diante dos agrupamentos discursivos do quais afirmarmos que a literatura tira partido:

É preciso também que nos inquietemos diante de certos recortes ou agrupamentos que já nos são familiares. É possível admitir, tais como são, a distinção dos grandes tipos de discurso, ou a das formas ou dos gêneros que opõem, umas às outras, ciência, literatura, filosofia, religião, história, ficção, etc., e que as torna espécies de grandes individualidades históricas? Nós próprios não estamos seguros do uso dessas distinções no nosso mundo de discursos, e ainda mais quando se trata de analisar conjuntos de enunciados que eram, na época de sua formulação, distribuídos, repartidos e caracterizados de modo inteiramente diferentes $[\ldots]^{23}$.

${ }^{22}$ FOUCAULT, Michel. Arqueologia do saber. 3ed. Trad. Luiz Felipe Baeta Neves. Rio de Janeiro: Forense Universitária, 1987.

${ }^{23}$ Idem, p. 24-25. 
Nesse mundo de discursos em que se constrói a literatura e a história os romancistas latino-americanos requerem para si o direito de atuar em ambos os discursos, ora imitando o historiador em seu trabalho, ora atuando como romancista que age somente sobre o material literário, parodiando, confrontando e reescrevendo duas histórias: a da literatura e a histórica, deixando o romance flutuante entre duas realidades também construídas discursivamente. De certa forma, essas discussões se resolvem ou se complicam apenas no âmbito dos discursos, justamente onde há as incertezas, as brechas, as fissuras, que o romancista resgata em si o historiador escondido e romanceia a história da América.

\section{Considerações finais}

Empreendemos ao longo desse artigo uma tentativa de apresentar o diálogo entre os discursos da história e o da literatura, apontando as imbricações que esses modelos discursivos apresentam, sendo a metaficção historiográfica essa zona intersticial em que História e histórias se enfrentam, na qual romancistas e historiadores se confundem, num diálogo tão intenso que, coloca-se em dúvida o discurso da História e o da ficção, a ponto de o leitor questionar a verdade em ambas e não apenas no romance.

Dessas inseguranças e mobilidades o leitor esquece o que é ficção e o que é história, de forma que o romance serve de instrumento desestabilizador de formas discursivas consagradas, muitas vezes preferindo, pela inventidade que apresenta, a versão romanesca, uma vez que encontra girando nesse espaço figuras históricas humanizadas, descidas de suas estátuas equestres e habitando o mundo dos mais comuns mortais que compõe a história das nações todos os dias.

O leitor latino-americano há muito já não suporta mais os heróis tradicionais das epopeias clássicas, embora alguns romancistas e historiadores ainda insistam em sacralizar hoje as personalidades históricas como heróis inatingíveis. O leitor sente-se mais à vontade com os novos romances históricos, nos quais há a tarefa transgressora de desafiar a história tradicional, de certa forma alimenta-se dessa transgressão e sente-se dono de uma história que durante séculos foi vista apenas pela visão herdada de um mundo eurocêntrico.

Foram justamente essas questões que abordamos ao decorrer do artigo, explicitando como a pós-modernidade trouxe consigo a vantagem de assumir a 
construção das representações do mundo como constructos discursivos e, portanto, passíveis de revisão, de releituras que não desprezam o passado, mas o incorporam como mais um elemento interpretativo da realidade, uma vez que a própria interpretação anterior também era discursiva.

Enfim, tentamos também por meio do discurso e de um recorte intencional, ao escolher os romances Vigilia del Almirante e Galvez, o imperador do Acre debater como os romancista latino-americanos propõem o diálogo com a história, revendo-a, mas sabendo que não têm a autoridade para substituir o discurso histórico compromissado com a verdade. Assim, não foi a nossa intenção fazer longas análises dos romances em si, mas selecionar fragmentos, cacos de uma realidade arquitetada ficcionalmente, para explicitar a intertextualidade presente entre a literatura e a história. 